\title{
The effectiveness of community-based programs for obesity prevention and control
}

This article was published in the following Dove Press journal:

Patient Intelligence

7 December 201 I

Number of times this article has been viewed

\section{Elizabeth Teixeira}

Drexel University College of Nursing and Health Professions, Philadelphia, PA, USA
Correspondence: Elizabeth Teixeira

I505 Race Street, Bellet Building,

Mail Stop \#50I, Philadelphia,

PA 19102, USA

$\mathrm{Tel}+2$ I 57626486

Fax +2I 5762 I259

Email met42@drexel.edu

\begin{abstract}
Obesity is a major public health concern worldwide. The increasing prevalence of obesity in all ages, especially children and adolescents, has gained global attention and it is widely known that obesity increases the risk of many chronic conditions and illnesses, such as Type 2 Diabetes Mellitus (T2DM) and cardiovascular disease (CVD). Obesity is a complex metabolic disorder, however, that is difficult to treat and manage. Therefore, despite the increased awareness about obesity-related health risks, obesity prevention and control has been a major challenge for health professionals. Lifestyle modification is easily prescribed, however, multiple barriers to implementation exist. Barriers include but are not limited to: behavioral and motivational factors, anti-fat bias, access to and reimbursement of educational programs, availability of healthy affordable foods, ongoing support systems that are culturally and community attuned, and comorbidities that limit physical activity and quality of life. Further, the current health care systems are not all designed to focus on health promotion and wellness. These contributing factors complicate weight management and control. Community-based programs are one potentially feasible approach that can assist individuals, families, and communities in developing healthy behaviors that promote and maintain weight loss. This review reports on nine worldwide current studies on the effectiveness of community-based programs in diverse populations targeting obesity. The purpose of this review is to examine evidenced-based interventions that can assist in the development of standard practices in the battle against obesity.
\end{abstract}

Keywords: obesity, community, prevention, physical activity, nutrition

\section{Introduction}

Obesity, a well-known worldwide epidemic, poses great health risks to all age groups, challenges health care providers, and, due to its associated chronic illnesses, contributes to the health care financial burden. Comorbidities are often associated with obesity, such as Type 2 Diabetes Mellitus (T2DM), asthma, sleep disorders, and cardiovascular disease (CVD). ${ }^{1}$ The above comorbidities have a significant threat to the obese population with their high rates of both morbidly and mortality. Further, the increase in obesity rates in the pediatric population is now an early predictor for the once adultonly chronic health problems such as T2DM and CVD. The statistics are alarming and have resulted in a global public health initiative to address the obesity epidemic.

In the US alone, obesity affects $34 \%$ of the adult population aged $\geq 20$ years and is increasing in the pediatric population. ${ }^{2}$ Obesity is rising in Europe's young as well, with up to one-third of adolescents meeting classification for overweight or obese. ${ }^{3}$ More startling is the increase of obesity-related medical problems such as T2DM. In the US, 25.8 million people have diabetes, while another 79 million have been 
diagnosed with pre-diabetes and are at risk of developing the disease. ${ }^{4}$ Even though adults aged $65-74$ years have the highest prevalence of diabetes, nearly $45 \%$ of newly diagnosed cases of diabetes among US children and adolescents are classified as T2DM. Furthermore, health disparities exist, with a disproportionate rate of T2DM among low income ethnic minority populations. Youth-based obesity is also higher in ethnic minority and low income families, influenced by culture and geography. ${ }^{5-7}$

Given the prevalence of obesity and its related health risks, the research is overwhelming that lifestyle modification and weight reduction can prevent or delay T2DM worldwide, a main goal of obesity prevention and control. ${ }^{8-10}$ Research has demonstrated that weight loss of $5 \%-7 \%$ can delay or reduce the risk of developing diabetes and its sequelae. ${ }^{11}$ However, even with the knowledge that a permanent lifestyle change is necessary to prevent weight gain, many individuals still struggle with their weight. Few evidenced-based programs have been successful in long-term weight loss. ${ }^{12}$ In practice, overweight and obese persons commonly lose weight, but gain the weight back and often within a short time frame. Gastric bypass surgery (ie, Roux-en-Y) recipients are no different, as many gain weight back and even return to their presurgical weight. Further, the long term benefits of gastric bypass surgery in the pediatric population are unknown. ${ }^{13}$ Therefore, ethical consideration and alternate approaches such as lifestyle modification are essential before referrals for gastric bypass surgery are recommended, especially in the pediatric population.

Adding to the conundrum is that even if weight-loss programs are abundant, access is often limited due to cost and convenience. Additional barriers to effective lifestyle counseling exist even in primary care. Perceived barriers by both practitioners and patients include, but are not limited to: time, frustrations by both parties, stigma of obesity, and a lack of knowledge on effective strategies to address weight-related concerns and education. ${ }^{14}$ Moreover, patients seen at primary care practices are often there for illness-related conditions that can hinder the best situation or environment for an educational program on healthier living. The stigma of obesity, one highly recognized barrier, is often associated with discrimination. This can impact providers' approach to patients and families to discuss weight reduction and may even contribute to health care avoidance by patients. ${ }^{15}$ Discussing weight issues is a sensitive topic that requires skilled counseling and support as well as dispelling myths about persons who are obese. Thus a major problem is creating an environment that will assist in changing behaviors for the long term and provide an atmosphere where the stigma of obesity is minimized. Therefore, community-based programs make perfect sense for facilitating a conducive learning environment that both minimizes barriers and provides optimal resources that can result in lasting positive lifestyle changes. Ultimately, the long-term goal is to achieve sustainable obesity prevention programs that improve the overall health and quality of life of individuals, families, and communities.

Given the constraints on many medical practices, community-based programs have several advantages. They are easily accessible to the population at hand, are culturally attuned, cost effective, and generally well received as the participants are part of the process. Typical settings for community based programs include schools, work sites, churches, and community centers, although any community setting is desirable. One theoretical framework for community-based interventions centers around the philosophy that individuals and families are more likely to engage in lasting healthy vital behaviors that are presented and supported by a culturally committed social group that have shared values and goals. ${ }^{16}$ Other theoretical bases that involve standalone or integrated interventions have had disappointing results. ${ }^{3}$ Therefore, the purpose of this review is to present current research that utilized community or public health approaches that targeted obesity and evaluated their effectiveness and sustainability.

Since obesity rates have increased in children and adolescents and the pediatric population is at the heart for many obesity prevention programs worldwide, the majority of research articles reviewed sampled children and teens at high risk. Studies reviewed primarily include middle school-aged children and teens as participants, often with low socioeconomic status, and in a variety of community settings. These included schools, community centers or clinics, churches, or some combination.

\section{Methods}

A thorough review of the literature was conducted utilizing the databases MEDLINE, CINAHL, and PsycINFO, spanning the years 2006 to the present. In addition to the electronic search, additional studies were reviewed and selected from each retrieved article's reference list. Research articles selected were published within the previous 5 years to provide the most current research on obesity prevention programs. Keywords used included the following: obesity, community, educational programs, prevention, population, public health. Nine studies were reviewed (See Table 1). 


\section{Pediatric programs}

Six studies reviewed utilized either a school or community environment to implement a program targeting obesity in children and/or adolescents. Four of the six studies conducted a randomized control trial (RCT) with a large sample; two however, have no published results. These latter studies are discussed as they present similar methods and in foreign countries. Two studies are quasi-experimental in design, the first a pilot study that was conducted in an Appalachian school setting and the second in the Atlanta, GA area with African American adolescents.

A 2-year obesity prevention RCT entitled 'Girl's Health Enrichment Multi-site Studies' (GEMS) with pre-teen African American girls was conducted in two major US urban areas: Memphis, TN and Stanford, CA. ${ }^{17,18}$ This study was done in collaboration with the National Heart, Lung, and Blood Institute. The two arm study had similar inclusion criteria but different interventions. Children aged 8-10 years and their parents or guardians were asked to participate and were randomly assigned into the intervention group or the control/attention-placebo group. All instructors were African Americans from within the community. Eligible girls were aged 8-10 years and had a body mass index (BMI) at or higher than the 25th percentile for their age or had one parent with a BMI of 25 or higher. Girls excluded from the study were those with a BMI greater than 35; had a diagnosed medical condition; were taking medication that could affect growth and development; or had any limitations that prevented participation in the intervention over the 2-year period.

The Memphis Tennessee site $(\mathrm{N}=303)$ settings were local community centers and Young Women's Christian Association (YWCAs) in the Memphis area. Eligible girls were randomized into either the group behavioral counseling intervention group or the self-esteem and social efficacy control group. In contrast, the Stamford site $(\mathrm{N}=261)$ randomized families (girls and parents or guardians) from low-income areas of Oakland, CA into either an after school combination dance class (hip-hop, African, and step) and home-based screen time reduction intervention group or the information-based health education (control group).

While both studies' primary outcome measure was BMI, they also had varied secondary outcome measures. Both arms of the GEMS found no decrease in BMI after 2 years, as well as no significant changes in anthropometrics, including weight circumference and tricep skinfold thickness. Although the Stamford study found no change in BMI between the groups in 2 years, the BMI gain was reduced in the subgroups of girls in the experimental intervention group who reported unmarried parents/guardians and/or reported more watched television at baseline. In comparison, the Memphis study found an increase in BMI in all girls with no treatment effect at 2 years (mean $0.09 \mathrm{~kg} / \mathrm{m}^{2}, 95 \%$ confidence interval [CI]: $-0.40-0.58$ ), with a mean BMI difference at 2 years of $-2.41 \mathrm{~kg} / \mathrm{m}^{2}$ in 8 -year-old girls at baseline and $-1.02 \mathrm{~kg} / \mathrm{m}^{2}$ in girls initially aged 10 years.

Both studies discovered significant findings on various secondary measures. First, in the Memphis GEMS study, a healthy behavior change in food choices was evident but with no effect on physical activity. Participants reported a decrease in sugar sweetened beverages and an increase in vegetable and water intake. In the Stanford study, clinically relevant reductions in lipid levels, insulin levels, and depressive symptoms were found. These secondary findings suggest that BMI alone is not sufficient to measure positive behavioral changes and perhaps lower cardiovascular risk (ie, improved lipid panel). More investigation is warranted to see if the trend continues over time with improved serum fasting total cholesterol, low density lipoprotein cholesterol, and insulin levels. Further investigation is essential to determine if these reductions alone are adequate to delay or prevent disease in this population.

Limitations included the homogeneous sample, narrow age range, study length and follow-up and subjective data collection. Subjective data such as reports of healthier food choices and less depressive symptoms could be biased by participants' willingness to please. However, since these findings were not shared by the control group it is more likely that the intervention did indeed have an effect on positive behaviors. Despite the reports of healthier food choices, the following may have influenced BMI results: food preparation, access to healthy foods, and cultural beliefs. Clearly, instruction in healthy eating is not sufficient to lose weight. Perhaps ways to prepare culturally traditional foods using less fat would have helped reduce calorie consumption and BMI.

An Australian RCT entitled 'The Nutrition and Enjoyable Activity for Teen Girls' (NEAT Girls) is currently in progress. ${ }^{19}$ This is a 12-month multi-component schoolbased intervention with a 1-year follow up (total 24 months), which includes a combination of workshops and seminars on nutrition and physical activity based on Social Cognitive Theory. Self-monitoring of physical activity with pedometers will be employed. The primary outcome measure is BMI. The study's aim is to prevent unhealthy weight gain and improve dietary habits and physical activity in teen girls with low socioeconomic status. Adolescent girls $(\mathrm{N}=357)$ from disadvantaged areas in twelve secondary schools were recruited 
Table I Descriptions of the study aims, methods, interventions, results, and limitations from nine selected community-based programs targeting obesity

\begin{tabular}{|c|c|c|c|c|}
\hline Authors & Study & Community setting & Study aims & Methods \\
\hline Stahl et $\mathrm{al}^{27}$ & $5-4-3-2-I \mathrm{Go} !^{27}$ & Health care clinics & $\begin{array}{l}\text { I. Feasibility of training } \\
\text { residents in brief behavioral } \\
\text { counseling } \\
\text { 2. Counseling, along with } \\
\text { community-based 5-4-3-2-I-Go! } \\
\text { message campaign, could } \\
\text { lead to positive changes in } \\
\text { children's eating and activity } \\
\text { behaviors }\end{array}$ & $\begin{array}{l}\text { I I } 3 \text { pediatric residents complete a }<60 \\
\text { minute online training module including } \\
\text { current dietary and PA recommendations } \\
\text { for children and teens and strategies for } \\
\text { approaching parents and teens } \\
\text { Pilot phase: I } 8 \text { residents in } 3 \text { COCs } \\
\text { Intervention phase: } 20 \text { additional } \\
\text { COCs with a total of } 28 \text { I participants } \\
\text { from active clinics and } 228 \text { from } \\
\text { control clinics }\end{array}$ \\
\hline Smith ${ }^{7}$ & $\begin{array}{l}\text { Teen mentors } \\
\text { to promote } \\
\text { healthy lifestyle } \\
\text { among children }{ }^{7}\end{array}$ & $\begin{array}{l}\text { School in } \\
\text { Appalachia, } \\
\text { United States }\end{array}$ & $\begin{array}{l}\text { Pilot study to assess the } \\
\text { effectiveness of teen } \\
\text { mentoring in promoting } \\
\text { healthy behaviors in } \\
\text { children in Appalachia }\end{array}$ & $\begin{array}{l}\text { Pre-test-post-test design } 72 \text { third } \\
\text { and fourth grade students randomly } \\
\text { assigned to either intervention group } \\
(\mathrm{N}=35) \text { or attention control } \\
\text { group }(\mathrm{N}=37) \text {. } \\
\text { Teen mentors were trained for } \\
6 \text { hours over } 2 \text { days }\end{array}$ \\
\hline Robinson et al ${ }^{18}$ & $\begin{array}{l}\text { GEMS in } \\
\text { Stamford, } \mathrm{CA}^{18}\end{array}$ & $\begin{array}{l}\text { School programs in } \\
\text { low income areas } \\
\text { of Oakland, CA }\end{array}$ & $\begin{array}{l}\text { The effect of a 2-year } \\
\text { community- and family-based } \\
\text { obesity prevention program } \\
\text { for low-income African } \\
\text { American girls on changes } \\
\text { in BMI }\end{array}$ & $\begin{array}{l}\text { RCT with follow-up measures } \\
\text { at } 6,12,18 \text {, and } 24 \text { months } \\
\mathrm{N}=26 \mathrm{I} \text { African American girls aged } \\
8-10 \text { years and their parents } \\
\text { or guardians }\end{array}$ \\
\hline Klesges et $\mathrm{al}^{17}$ & $\begin{array}{l}\text { GEMS in } \\
\text { Memphis, } \mathrm{TN}^{17}\end{array}$ & $\begin{array}{l}\text { Community centers } \\
\text { and YWCAs in the } \\
\text { Memphis area }\end{array}$ & $\begin{array}{l}\text { The effect of a 2-year } \\
\text { community- and family-based } \\
\text { obesity prevention program } \\
\text { for low-income African } \\
\text { American girls on } \\
\text { changes in BMI } \\
\text { (Multi-site study - Memphis GEMS) }\end{array}$ & Girls aged $8-10$ years $(N=303)$ \\
\hline Briancon et $\mathrm{al}^{3}$ & PRALIMAP ${ }^{3}$ & $\begin{array}{l}24 \text { high schools } \\
\text { in France }\end{array}$ & $\begin{array}{l}\text { Improve obesity prevention } \\
\text { programs in adolescent } \\
\text { Focus on clustering, multiple } \\
\text { factorials, and long-term duration }\end{array}$ & $\begin{array}{l}\text { Stratified } 2 \times 2 \times 2 \text { factorial } \\
\text { cluster RCT } \\
24 \text { high schools, } \\
5458 \text { adolescents }\end{array}$ \\
\hline Assuncão et $\mathrm{al}^{26}$ & $\begin{array}{l}\text { Individualized } \\
\text { educational } \\
\text { program }^{26}\end{array}$ & $\begin{array}{l}\text { Nutrition } \\
\text { outpatient clinic } \\
\text { in Pelotas, Brazil }\end{array}$ & $\begin{array}{l}\text { To assess the effectiveness } \\
\text { of an educational intervention } \\
\text { on how to lose weight } \\
\text { and prevent other chronic } \\
\text { noncommunicable disease }\end{array}$ & $\begin{array}{l}\text { Patients were randomly assigned } \\
\text { to either the IG }(N=I 20) \text { or } \\
\text { CG }(N=I 2 I) \text {. } \\
\text { The IG received individualized } \\
\text { nutritional counseling for } 6 \text { months and } \\
\text { the control group received usual care }\end{array}$ \\
\hline Annesi $^{29}$ & $\begin{array}{l}\text { Youth Fit } \\
\text { for life }\end{array}$ & $\begin{array}{l}\text { School-based. } \\
\text { After school or } \\
\text { during physical } \\
\text { education class } \\
\text { Georgia area }\end{array}$ & $\begin{array}{l}\text { To examine the Youth Fit } \\
\text { For Life treatment in African } \\
\text { American pre-adolescents }\end{array}$ & $\begin{array}{l}200 \text { African American pre-adolescents } \\
\text { age } 7-12 \text { years who were either } \\
\text { classified as normal, overweight, } \\
\text { or obese weights }\end{array}$ \\
\hline Lubans et al ${ }^{19}$ & NEAT Girls ${ }^{19}$ & $\begin{array}{l}\text { I2 secondary } \\
\text { schools in Australia }\end{array}$ & $\begin{array}{l}\text { To assess the effect of the } \\
\text { Nutrition and Enjoyable Activity } \\
\text { for Teen Girls (NEAT) } \\
\text { intervention for girls from } \\
\text { disadvantaged secondary schools }\end{array}$ & $\begin{array}{l}\text { Group RCT } \\
\text { CG: } 6 \text { schools, } n=179 \\
\text { IG: } 6 \text { schools, } n=178\end{array}$ \\
\hline
\end{tabular}




\begin{tabular}{l} 
Intervention \\
\hline Clinic-based counseling using the \\
behavioral planning sheet and \\
5-4-3-2-I-Go! message \\
by trained residents \\
Community Education campaign utilizing \\
the 5-4-3-2-I-Go! flyer targeting \\
children, mainly in schools and park \\
programs
\end{tabular}

Intervention group received the Just for Kids! curriculum by trained high school teen mentors I hour a week for 8 weeks Control group received I hour structured after school activities by teens employed by the school's After School Network Program

Intervention group participated in after school dance classes

Control group participated

in information-based health education

Randomized into either the intervention group behavioral counseling that promoted healthy eating and exercise or self-esteem and social efficacy (attention-placebo group)

Intervention groups will receive an educational strategy consisting of nutritional lessons, working groups, and a final party over 2 academic years

IG received individualized nutritional care for 6 months

CG received individualized usual care

12 week 3 days per week for 45-minute sessions in moderate-to-high intensity exercise alternating with resistance exercises

Randomized by school into either the intervention or control group

\section{Results \\ Resident training:}

I 3 trained residents performed significantly better on the post-test compared to pre-test

Patient/parent interviews: those that received counseling from trained residents reported more positive changes in behaviors $(P<0.01)$ on increased intake of fruits and vegetables, water, and PA than control and more likely to report being successful in their plan (36\% vs $19 \%, P<0.03)$

Significant increase in behavioral intention to eat healthfully in the teen mentoring group but not in behavioral intention to engage in PA

Significant increase in nutritional knowledge in mentored group

Significant reduction in BMI in intervention group $(P=0.03)$

Attention control group had a decrease in all theoretical concepts with the exception of self-efficacy. Significant improvement in self-efficacy toward PA $(P=0.05)$

BMI did not differ between groups Reductions in the following secondary measures: total cholesterol, LDL, hyperinsulinemia incidence and depressive symptoms

BMI increased in all girls with no treatment effect at 2 years

Trend toward decrease in sweetened beverages, increase water and vegetable servings

No increase in physical activity

Not available

Mean fasting glycemia and daily consumption of sweet foods and sodium reduced

Increase in time spent on PA in IG

Individuals from IG lost more in body weight, waist circumference, and fasting glucose compared to CG

Reductions in BMI were greater in the overweight and obese groups than normal weight group

Overweight/obese groups did not differ

Not available

Limitations

No randomization of patients/parents to intervention or control groups, which could result in selection bias Resident fidelity to the counseling technique not assessed Relationship of reported behavior changes not correlated with BMI

No direct observation of actual behavior changes Lack of long-term follow-up

Missing data at follow-up visits 2 and 3 Low attendance rates at dance classes (median II.6\%, one-fifth of the goal rate)

Narrow age range Need for make-up sessions in intervention group Response bias on questionnaires

Not available

Length of follow-up only 6 months Both groups received care by nutritionists

Lack of control group

Self-report for physical activity

Not available 
Table I (Continued)

\begin{tabular}{|c|c|c|c|c|}
\hline Authors & Study & Community setting & Study aims & Methods \\
\hline Goldfinger et $\mathrm{al}^{24}$ & Project $\mathrm{HEAL}^{24}$ & Harlem, NY church & $\begin{array}{l}\text { Pilot on the effect of a } \\
\text { peer-led, community-based } \\
\text { course on weight loss } \\
\text { behavior change, and } \\
\text { health-related QOL in a } \\
\text { predominantly minority } \\
\text { community }\end{array}$ & $\begin{array}{l}26 \text { African American ( } 2 \text { I female) } \\
\text { participated in Project HEAL in a local } \\
\text { church } \\
\text { All participants expressed interest } \\
\text { and volunteered for program }\end{array}$ \\
\hline
\end{tabular}

in May/June 2010 and randomly assigned to either the NEAT Girls intervention $(\mathrm{N}=178)$ from six schools or the control group $(\mathrm{N}=179)$ from the other six schools. The timeline for data collection is at 12 months (May/June 2011) and 24 months (May/June 2012). When the data becomes available, it will be crucial to examine and compare these results with the GEMS 2-year RCT findings, especially on BMI.

A stratified group $2 \times 2 \times 2$ factorial cluster RCT (PRALIMAP) was conducted in France with 24 high schools and over 5000 teens in two waves: the first in 2006 and the second in $2007 .^{3}$ Three public health promotion strategies were implemented either singly or in combination: educational, screening, and environmental. The primary goal of this study was to determine the best approach to implement effective obesity prevention programs (lifestyle modification) in the school environment. Teens were selected on the premise that this age group is at a stage of development that can foster positive health attitude behaviors through empowerment. Outcomes measures obtained at baseline and follow-ups included anthropometry (weight, height, and waist circumference), nutritional knowledge, attitudes and behaviors obtained by a quiz, the Eating Attitudes Test 40 (EAT-40) questionnaire, and the Hospital Anxiety and Depression (HAD) questionnaire. The EAT-40 was used to screen for eating disorders and HAD to screen for anxiety or depression. Results of this study are not yet published.

In contrast to the BMI results in the GEMs studies, the following two studies found significant reduction in BMI. In the first study, African American pre-adolescents $(\mathrm{N}=200)$ were found to have greater reductions in BMI among the overweight/obese group than children of healthy weights. ${ }^{20}$ Children aged 7-12 years old participated in a 12-week program based on the Youth Fit for Life protocol. This was implemented either at an after-school program or during physical education classes. The participants were asked to attend three 45-minute sessions per week for
12 weeks. Each session included a moderate-to-high intensity cardiovascular workout alternating with resistance exercises. In addition to BMI, self-reported data collected included: log on weekly physical activity, physical self-concept subscale, and exercise barriers self-efficacy scale. Data was collected at baseline and again at 12 weeks. No follow-up was conducted. Results found a significantly greater reduction in BMI in the overweight/obese $(\mathrm{N}=61)$ than the normal weight group $(\mathrm{N}=139)\left(\mathrm{t}_{198}=5.26 . P<0.001\right)$. In addition, the effect sizes for BMI change were also greater for the overweight/obese $(d=0.25)$ than the normal weight group $(d=0.15)$.

A different approach was utilized in a pilot study with children in Appalachia. ${ }^{7}$ Trained teen mentors were paired with younger children in an after school environment to provide educationally relevant material and activities to promote healthy behaviors. Third and fourth grade students $(\mathrm{N}=72$ ) with BMIs ranging from underweight to obese (BMI at or greater than 95 th percentile) were randomly assigned to either the teen mentoring intervention group or the attention control group. The Just for Kids! curriculum was modified and delivered by the trained high-school teen mentors. ${ }^{21}$ The participants received a 1-hour after-school program related to healthy nutrition and physical activity for a total of 8 weeks. The primary outcome measure was BMI. Secondary measures included self-report scales on nutritional knowledge and attitudes, self-efficacy, perceived autonomy and intention on eating healthfully and being physically active.

The results showed a significant reduction of BMI percentile $(\mathrm{t}[25]=-2.196 . P=0.03)$ in the mentored group and an increase in knowledge, attitudes, efficacy, and perceived support on eating healthy and being physically active. Most impressive was the change in BMI from pre-test and post-test scores after only 8 weeks. Of the 35 children mentored, the number of children in the healthy weight category doubled from eight children to 16 children with a decrease in the number of children 


\begin{tabular}{lll}
\hline Intervention & Results & Limitations \\
\hline Professionally led program with & Mean loss of $4.4 \mathrm{lbs}$ at I0 weeks & Lack of control group \\
8 sessions over I0 weeks & Mean body weight at I year was I85 lb compared & Homogeneous sample \\
$\begin{array}{l}\text { Measurement of weight and height and } \\
\text { calculated BMI }\end{array}$ & $\begin{array}{l}\text { to a mean of I } 94.3 \mathrm{lb} \text { at onset of study } \\
\text { Perceived health-related QOL improved } \\
\text { Demographic survey }\end{array}$ & \\
$\begin{array}{l}\text { Survey on knowledge, attitudes and } \\
\text { behaviors including body image, }\end{array}$ & \\
$\begin{array}{l}\text { sepressive symptoms and perceived } \\
\text { health-related QOL }\end{array}$ & & \\
\hline
\end{tabular}

Abbreviations: BMI, body mass index; CG, control group; COCs, Continuity of Care clinics; GEMS, Girl's Health Enrichment Multi-site Studies; HEAL, Healthy Eating, Active Lifestyles; IG, intervention group; NEAT, Nutrition and Enjoyable Activity for Teen Girls; QOL, quality of life; PA, physical activity; RCT, randomized control trial.

classified as obese (from 17 to 1 ) with no improvement in the attention-control group. In fact, the number of children classified as obese increased from ten to 15 in the attentioncontrol group after the 8 -week period. Reasons for these differences were not addressed. Important to note is that no anthropometrics were assessed in this study (waist circumference or skin-fold measures), which may have influenced results. However, BMI has been suggested as the most precise measure of adiposity changes in children and is commonly used in research. ${ }^{22}$

Limitations of this study include the small sample, gender differences (nearly two-thirds were female), follow-up, and measures of actual or vital behaviors being observed or reported. Clearly, further studies are warranted to investigate the modified Just for Kids! curriculum after-school program utilizing teen mentors. A larger sample and 2-year follow-up is recommended. It would be prudent to also investigate the environment in which such behavioral changes took place since family members were not included as participants. Considerations for future investigation include additional factors that led to the childrens' reduction in BMI, what actual behavioral changes occurred, and in what environment(s). In other words, did children eat healthier at school only, or continue to implement these changes at home and in other settings? Also, factors related to the increase in BMI in the control group should be explored.

\section{Community action research with adults}

Community participatory research or action research is developed and executed in collaboration with all stakeholders within that community. Before the research begins, meetings with community leaders and members are frequent. Focus groups are common to establish the specific needs of the community (individuals and families) and bring to light potential barriers and concerns that could negatively affect the research. The community participants are involved from start to finish, from the proposal phase, to planning and implementation, to program evaluation. ${ }^{23}$

A pilot study $(\mathrm{N}=26)$ with African American adults is an example of community participatory approach to obesity research. The study was conducted using a peer-led, community-based healthy living course entitled 'Project HEAL: Healthy Eating, Active Lifestyles'. ${ }^{24}$ This weight-loss program was developed by a team of nutritionists, health professionals, and outreach workers from within the Harlem, NY area. The team responded to a request by a church in Harlem, where all the participants were recruited. Eight 90-minute sessions over 10 weeks were held at the church. The primary outcome measure was weight and secondary outcome measures included self-reported behaviors and quality of life. Data was collected at baseline and repeated at 10, 22, 32 weeks and 1 year.

Before beginning the program, local survey and focus groups were conducted to identify barriers to weight loss in these community dwellers and assess relevant dietary and exercise take home messages. From the information collected, the team developed the weight-loss curriculum for this peer-led course. Key messages addressed included the following: portion control, filling half the plate with fruits and vegetables, reducing fat, drinking calorie-free beverages, being more active, and eating healthy foods from takeout and on a budget. ${ }^{24}$

The results from this study are impressive. The 26 participants had a statistically significant reduction in BMI as well as a mean loss of weight from $4.4 \mathrm{lb}(P<0.001)$ at 10 weeks to nearly $10 \mathrm{lb}$ or $5 \%$ of their initial body weight at 1 year. There were several study limitations, including sample bias (homogeneous group), small sample size, and lack of a control group. However, the findings suggest that a peer-led community-based weight-loss program has the potential of sustainability. Motivated participants or groups can continue 
the lifestyle changes with shared knowledge and support, and perhaps a shared faith. It would be interesting to know if these 26 individuals continued meeting together after the 10-week course concluded. This would help support the idea of self/ group management within the environment (neighborhood) versus outside (medical practices). One might assume since these 26 individuals were congregants of the same church and expressed a shared interest in the weight-loss program that this contributed to the study's positive outcome.

The PRALIMAP trial nearly qualifies as action research. ${ }^{3}$ The distinction is that in this trial external-trained health education professionals (from outside the schools) were recruited to act as 'monitors'. These individuals oversaw the process from objectives to activities. In contrast, in action research these 'monitors' would be the individuals most invested in the initiative (teachers, parents, and students). Even though teachers were involved in the implementation of the program and part of the evaluation process, it exhibits more of a 'backdoor' approach. Information was gathered over 2 years on the content, delivery, and stakeholders input. Perhaps having the stakeholders develop the program would have had a different effect. Unfortunately, no published results were found after a thorough literature search.

\section{Public health programs}

In the US, primary focus of the public health system has been on the prevention and control of infectious communicable diseases. However, with vast improvements in infectious disease control, there has been a rise in chronic disease. Lifespan has increased with advances in medicine and technology to treat diseases such as cancer and diabetes. Zhang and colleagues conducted a cross-sectional analysis of 2300 Local Health Departments retrieved from the 2005 National Profile of Local Health Departments nationwide. ${ }^{25}$ The goal was to assess the number of obesity prevention and diabetes screening programs. The results are as follows: $56 \%$ of Local Health Departments had obesity prevention programs, $51 \%$ had diabetes screening programs, and $34 \%$ had both. However, no information was provided on the frequency of services obtained, effectiveness, or cost. The following reviewed studies utilized obesity prevention and weight-loss programs in public health or clinic settings.

\section{Outpatient clinic-based programs}

One study that utilized a country's public health system focused on providing an individualized educational program to reduce weight and control risk factors for related chronic diseases. ${ }^{26}$ The intervention was implemented at the Nutrition
Outpatient Clinic of a hospital in Pelotas, Brazil. Participants aged 20 years or older were randomized into either the intervention group (IG; $n=120)$ or control group (CG; $n=121)$. For a total of 6 months, the IG received monthly individualized nutritional counseling and the CG received the clinic's usual care monthly. A total of 192 individuals completed the study (IG; $n=97),(C G ; n=95)$. Results found no statistical significance in weight loss (BMI) between groups; however, three individuals in the IG achieved a BMI $<24.9 \mathrm{~kg} / \mathrm{m}^{2}$ and none in the CG attained normal BMIs. Positive findings included a reduction in mean fasting glucose and daily consumption of sweet foods and sodium in the IG. Physical activity also increased in the IG while decreasing in the CG.

In another study, Stahl and colleagues investigated the feasibility and effectiveness of trained residents to execute a clinic-based behavioral intervention that promotes healthy eating and increased physical activity in children and families in the Chicago, IL area. ${ }^{27} \mathrm{~A}$ marketing piece to increase awareness of the initiative was also employed, with flyers for the '5-4-3-2-1 Go!' community-based education disseminated. The 113 residents that participated in the webbased training performed significantly better on the post-test, compared to pre-test in specific knowledge on nutritional facts, such as recommended daily servings and portion size, and recommended physical and sedentary times. They were then asked to counsel patients at their respective clinics using the behavioral planning sheet and collect contact cards for a 4-week follow-up phone interview. Results found more patients of trained residents reported positive changes in behaviors associated with lower obesity rates: increase in fruits and vegetables, water, increased physical activity, and decrease in television time. Although, the 5-4-3-2-1 Go! message seems feasible, the study limitations include the subjectivity of data and study fidelity.

\section{Discussion}

Several of the studies reviewed in this paper identified BMI as the primary outcome measure. While the rational for this choice is obvious, it is concerning given that significant reductions in BMI have not been observed in the majority of youth obesity prevention programs. ${ }^{20,28}$ Even though no significant changes in BMI were found in the GEMS studies, a significant reduction in BMI was found in the Appalachian teen-mentored program. ${ }^{7}$ This is one of the first known studies to show dramatic decrease in BMI in children utilizing intervention that promoted healthier eating and physical activity. Some of the variance, however, may be due to the rate of growth in participants. Since normal, overweight and 
obese children participated, the increase in the number of children to normal weight at the conclusion of the study may be due to ceiling effect sizes of BMI. ${ }^{29}$ Goldfinger et al also found a decrease in BMI in 26 adults at 10 weeks (end of intervention) and at the 1-year follow-up. ${ }^{24}$ The small sample in both studies limits the generalizability of the results, but serious consideration of a RCT with a larger sample in both groups is encouraged.

Several of the studies reviewed found statistical significance in various secondary outcome measures that may improve overall health and reduce disease risk. Improvements were found in the following measures: healthy food choices, health-related quality of life, serum lipid and insulin levels, depressive symptoms and knowledge, attitudes, efficacy, and perceived support on eating healthy and being physically active. Important to consider is that reductions in lipoprotein and insulin levels may be a better indicator of risk reduction for T2DM and CVD than BMI. It is known that weight (as measured in BMI) itself is not a determinant of poor health or disease risk but rather fat distribution, genetics, serum markers, and dietary consumption including types of fats. For example, the Mediterranean diet, high in polyunsaturated fatty acids, has been shown to decrease cardiovascular risk independent of weight. Other considerations include awareness that in some cultures being overweight or obese is more acceptable. For example, in one study, Mexican American women reported being more comfortable with a larger body size..$^{30}$

\section{Conclusion and practice implications}

Clearly obesity is a global problem affecting children, families, and communities. The increased risk for chronic disease and their complications is evident. Children that are overweight and obese have prompted national and global community initiatives involving schools, families, community centers, and other organizations to fight this battle. The stakes are high, as today's children have an increased risk of developing and living with chronic disease for their lifetime.

Part of the problem involves several barriers, both internal and external, that contribute to the refractory nature of obesity and diabetes management. ${ }^{31}$ Access barriers such as transportation and costs to prevention programs are well known. More discrete potential barriers include stigmatization and discrimination toward persons who are obese that poses great challenges. Individual perceptions of how they will be perceived and treated because of their weight affects psychological functioning and can factor into why persons stop weight-loss programs and diabetes care..$^{32}$ Motivational strategies that influence lifelong healthy eating and physical activity are difficult. Therefore, successful programs developed with a combination of social, psychological, cultural, and spiritual concepts in addition to science are suggested.

Practice implications include the continuation of identifying subpopulations at highest risk for T2DM and CVD and developing community-based initiatives tailored to each subpopulation. This approach may have the best potential for sustainable interventions that demonstrate positive attitudes and behaviors toward healthy living. Individualized versus group programs need further investigation. Advantages to individualized counseling may include preference, satisfaction, and tailoring to meet the specific needs of the individual. Individualized counseling, while having clear benefits, demands more time and costs that make this approach less feasible for obesity prevention and control. Noteworthy is that in the study by Assuncão et al that utilized an individualized nutritional program, attrition was equally high in both groups. ${ }^{26}$ In comparison, the school-based programs and action research had relatively low attrition rates over a longer follow-up period.

Although several studies have shown that positive attitudes and behaviors can result from obesity prevention programs, several have not shown a significant reduction in BMIs. This is disappointing since weight loss is the number one preventative and maintenance measure for T2DM. Future studies are warranted that utilize qualitative methods such as focus groups to get at the specific barriers to long-term weight-loss in individuals and groups. The successful weight loss results after 1 year by Goldfinger and colleagues suggest that community-based participatory research may be a better approach to obesity prevention. ${ }^{24}$ Further studies are warranted with large samples with follow-up longer than 2 years.

\section{Disclosure}

The author reports no conflicts of interest in this work.

\section{References}

1. Fox CS, Pencina MJ, Wilson PW, Paynter NP, Vasan RS, D'Agostino RB Sr. Lifetime risk of cardiovascular disease among individuals with and without diabetes stratified by obesity status in the Framingham heart study. Diabetes Care. 2008;31(8):1582-1584.

2. Center for Disease Control and Prevention. New CDC study finds no increase in obesity among adults; but levels still high. 2007. Available at: http://www.cdc.gov/nchs/pressroom/07newsreleases/obesity.htm. Accessed on September 1, 2011. 
3. Briancon S, Bonsergent E, Agrinier N, et al. PRALIMAP: study protocol for a high school-based, factorial cluster randomized interventional trial of three overweight and obesity prevention strategies. Trials. 2010;11:119.

4. American Diabetes Association. 2011 national diabetes fact sheet. Available at: http://www.diabetes.org/diabetes-basics/diabetesstatistics/?utm_source=WWW\&utm_medium=DropDownD. Accessed August 10, 2011.

5. Naravan KM, Boyle JP, Thompson TJ, Sorensen SW, Williamson DF. Lifetime risk for diabetes mellitus in the United States. JAMA. 2003;290(14):1884-1890.

6. Trivedi AN, Zaslavsky AM, Schneider EC, Ayanian JZ. Trends in the quality of care and racial disparities in Medicare managed care. $N$ Engl J Med. 2005;353(7):692-700.

7. Smith LH. Piloting the use of teen mentors to promote a healthy diet and physical activity among children in Appalachia. J Speci Pediatr Nurs. 2011;16(1):16-26.

8. Pan XR, Li GW, Hu YH, et al. Effects of diet and exercise in preventing NIDDM in people with impaired glucose tolerance. The Da Qing IGT and Diabetes Study. Diabetes Care. 1997;20(4):537-544.

9. Lindström J, Peltonen M, Tuomilehto J. Lifestyle strategies for weight control: experience from the Finnish Diabetes Prevention Trial. Proc Nutr Soc. 2005;64(1):81-88.

10. Knowler WC, Barrett-Connor E, Fowler SE, et al. Reduction in the incidence of type 2 diabetes with lifestyle intervention and metformin. N Engl J Med. 2002;346(6):393-403.

11. Center for Disease Control and Prevention. CDC's LEAN Works!: A workplace obesity prevention program 2011. Available at: http:// www.cdc.gov/leanworks. Accessed November 14, 2011.

12. Dansinger ML, Tatsioni A, Wong JB, Chung M, Balk EM. Meta-analysis: the effect of dietary counseling or weight loss. Ann Intern Med. 2007;147(1):41-50.

13. Apovian CM, Baker CL, Ludwig DS, et al. Best practice guidelines in pediatric/adolescent weight loss surgery. Obes Res. 2005;13(2): 274-282.

14. Ashley JM, St Jeor ST, Schrage JP, et al. Weight control in the physician's office. Arch Intern Med. 2001;161(13):1599-1604.

15. Teixeira ME, Budd GM. Obesity stigma: a newly recognized barrier to comprehensive and effective type 2 diabetes management. $J$ Am Acad Nurse Pract. 2010;22(10):527-533.

16. Patterson K, Grenny J, Maxfield D. Influencer: The Power to Change Anything. New York: McGraw-Hill; 2008.

17. Klesges RC, Obarzanek E, Kumanyika S, et al. The Memphis Girls' health Enrichment Multi-site Studies (GEMS): an evaluation of the efficacy of a 2-year obesity prevention program in African American girls. Arch Pediatr Adolesc Med. 2010;164(11):1007-1014.

18. Robinson TN, Matheson DM, Kraemer HC, et al. A randomized controlled trial of culturally tailored dance and reducing screen time to prevent weight gain in low-income African American girls: Stamford GEMS. Arch Pediatr Adolesc Med. 2010;164(11):995-1004.
19. Lubans DR, Morgan PJ, Dewar D, et al. The Nutrition and Enjoyable Activity for Teen Girls (NEAT girls) randomized controlled trial for adolescent girls from disadvantaged secondary schools: rationale, study protocol, and baseline results. BMC Public Health. 2010;10:652.

20. Amnesi JJ. Initial body mass index and free-time physical activity moderate effects of the Youth Fit for Life treatment in African-American pre-adolescents. Percept Mot Skills. 2010;110(3 Pt 1):789-800.

21. Johnson S, Mellin L. Just for Kids! San Anselmo, CA: Balboa Publishing. 2003.

22. Cole TJ, Faith MS, Pietrobelli A, Heo M. What is the best measure of adiposity change in growing children: $\mathrm{BMI}, \mathrm{BMI} \%$, BMI z-score or BMI centile? Eur J Clin Nutr. 2005;59(3):419-425.

23. Reifsnider E, Hargraves M, Williams KJ, Cooks, Hall V. Shaking and rattling: developing a child obesity prevention program using a faithbased community approach. Fam Community Health. 2010;33(2): 144-151.

24. Goldfinger JZ, Arniella G, Wylie-Rosett J, Horowitz CR. Project HEAL: peer education leads to weight loss in Harlem. $J$ Health Care Poor Underserved. 2008;19(1):180-192.

25. Zhang X, Luo H, Gregg EW, et al. Obesity prevention and diabetes screening at local health departments. Am J Pub Health. 2010;100(8):1434-1441.

26. Assuncão MC, Gigante DP, Cardoso MA, Sartorelli DS, Santos IS. Randomized, controlled trial promotes physical activity and reduces consumption of sweets and sodium among overweight and obese adults. Nutr Res. 2010;30(8):541-549.

27. Stahl CE, Necheles JW, Mayefsky JH, Wright LK, Rankin KM. 5-4-3-2-1 Go! Coordinating pediatric resident education and community health promotion to address the obesity epidemic in children and youth. Clin Pediatr (Phila). 2011;50(3):215-224.

28. Stice E, Shaw H, Marti CN. A meta-analysis review of obesity prevention programs for children and adolescents: the skinny on interventions that work. Psychol Bull. 2006;132(5):667-691.

29. Annesi JJ, Marti CN, Stice E. A meta-analytic review of the youth fit for life intervention for effects on body mass index in 5- to 12-year-old children. Health Psychol Rev. 2010;4:6-21.

30. Petti YM, Cowell JM. An assessment of measures of body image, body attitude, acculturation and weight status among Mexican American women. J Am Acad Nurse Pract. 2011;23(2):84-91.

31. Simmons D, Lillis S, Swan J, Haar J. Discordance in perceptions of barriers to diabetes care between patients and primary care and secondary care. Diabetes Care. 2007;30(3):490-495.

32. Friedman KE, Reichmann SK, Costanzo PR, Zelli A, Ashmore JA, Musante GJ. Weight stigmatization and ideological beliefs: Relation to psychological functioning in obese adults. Obes Res. 2005; 13(5):907-916.
Patient Intelligence

\section{Publish your work in this journal}

Patient Intelligence is an international, peer-reviewed, open access journal that characterizes and measures the central role of patient behavior and intention in optimizing healthcare management in all areas of disease and complaint types. An improved understanding of patient intelligence coupled with predictive analysis helps an organization contribute more effectively to achieving better outcomes. Submit your manuscript here: http://www.dovepress.com/patient-intelligence-journal

\section{Dovepress}

The journal is characterized by the rapid reporting of reviews, original research, methodologies, analytics, modeling, clinical studies and patient surveys across all disease areas. The manuscript management system is completely online and includes a very quick and fair peer-review system. Visit http://www.dovepress.com/ testimonials.php to read real quotes from published authors. 